\title{
An acoustic perspective on nature- based tourism experience - The soundscape of dog sledding, Lapland
}

Ivan Fesenko, University of Lapland, Multidimensional Tourism Institute (MTI) José-Carlos García-Rosell, University of Lapland, Multidimensional Tourism Institute (MTI)

Recently, there has been a growing interest in understanding the relationship between sounds and the co-creation of tourism experience. For instance, an interdisciplinary research group formed by scholars from five European universities is currently exploring the acoustic experience of tourists visiting urban destinations by using the case of Lisbon. The study is part of a three-year research project called "Sounding out the Tourist City". In Finland, the Lapland marketing and communication company House of Lapland and Visit Finland launched in April a new campaign called "Sound of Lapland", which offers a collection of authentic sounds taken from the wilderness and local life in Finnish Lapland. Although the relevance of sounds as part of tourism spaces has begun to be acknowledged across both academia and industry, there is still a limited body of literature on the subject (Liu, Wang, Liu, Yao, \& Deng, 2018). The focus of the literature has been on three research perspectives: noise pollution and its impact on tourist experiences (e.g. Mace, Corser, Zitting, \& Denison, 2013; Pilcher, Newman, \& Manning, 2009), the importance of natural quiet acoustic environments (e.g. Rantala \& Valtonen, 2014; Valtonen \& Veijola, 2011) and the role of sound as an element of multisensory experiences (e.g. Quan \& Wang, 2004; Waitt \& Duffy, 2010).

As Barry Truax (2012, p. 194) argues, "sound is not merely information exchange, but is capable of creating relationships between individuals and their environment in a dynamic process of embodied cognition". Indeed, a sound shapes not only the quality and character of a place but also our understanding of that place in particular (Bernat, 2014). Thus, we discuss here some of the acoustic elements shaping nature-based tourism experiences by drawing upon the notion of soundscape. Truax (1999) defines a soundscape as an environment of sound (or sonic environment) with an emphasis on the way it is perceived and understood by the individual, or by society. To illustrate the characteristics of a nature-based tourism soundscape and its impact on tourism experiences we use the case of dog sledding in Rovaniemi, Finnish Lapland. To that end, we based our discussion on interviews conducted in this Arctic destination during the 
winter season of 2018 (Fesenko, 2019). The research note is based on the master thesis "Sensory dimension of tourist experiencescape: role of sounds in winter husky dog-sledding experiences in Finnish Lapland" written by the first author under the supervision of the second author.

\section{The husky tour soundscape}

According to R. Murray Schafer (1983), a soundscape consists of three main elements: keynote sound, soundmark and signal. A keynote sound refers to a sound that may not always be heard consciously, but it is characteristic of a place. The traffic noise in urban areas is a typical example of a keynote sound. A soundmark, just like a landmark, indicates a sound that is unique and serves as a distinguishing feature of a place in particular. A good example of a soundmark would be the sound of Big Ben in London. A signal is a foreground sound that is listened to consciously. Acoustic warning devices such as bells and sirens are examples of signals. What does a nature-based tourism soundscape look like? What kind of keynote sounds, soundmarks and signals are highlighted in a nature-based tourism context? What is the role of these sounds in creating (or destroying) authentic nature-based tourism experiences? To shed some light on these questions, we discuss findings from nine interviews conducted with tourists participating in dog-sledding safaris in Rovaniemi, Finnish Lapland. The interviewees represented six different nationalities, both genders and an age range of 25 to 45 . The interviews were conducted in English between March and April 2018. The interviews helped identify keysounds, soundmarks and signals that arose in dog-sledding safaris.

The sound of the wind and the sled moving on the snow were identified as keynote sounds of the dog-sledding safari. As one of the interviewees expressed, "I think the sound you always have in the background will be the sound of sledges moving quite fast". Also, the sound of the brake, a loud distinctive sound made by a metal brake biting into the snow, was viewed as a sound that was intrinsic to the safari experience. As another respondent noted, "they were always pushing the brake and come on! It was not so fast, always taking care not to drive, not to bump". This draws attention to how technical aspects of the safari, such as the number of sleds in a row, safety and people's fear, may put constraints on speed and cause the appearance of keynote sounds that are unwanted or unpleasant, but become a keynote sound of the whole experience.

A soundmark that was perceived as a unique sound distinguishing the safari from the kennels was the barking of dogs. As one of the tourists highlighted, "probably what makes it [barking] sort of unique is that intensity in terms of having so many dogs in one place". Almost all respondents agreed that the barking was louder and more intense than any other barking they had heard before. Those who had already experienced a husky safari were able to recognize the various types of barks or howling that occurred during the safari. The barking at the beginning of the safari had a particular meaning for these tourists: "We would notice the howling like: "We want to go again!', so then you are already in the woods, but to other people who never had the experience it's just a bark." 
The signals identified in the husky safari are related to modernization and human-related practices. One of the signals noticed by the respondents was the sound of aeroplanes taking off, landing and flying over Rovaniemi. Air traffic in Rovaniemi is considerable due to the civil and military function of the airport. This sound was not always perceived as negative, as one of the tourists noted: "As soon as we started going it was amazing, it was great! The air force in the background." Nevertheless, all respondents regarded it as too loud, disturbing and destroying the feeling of being in the wilderness. It also made tourists feel very close to modern civilization, as noted by another tourist: "because you think you are out on your own in the middle of nowhere and then there's an aeroplane, 'Oh, we are not out there'."

Other signals identified included the sounds of other people talking, as one interviewee noticed: "Sometimes when you are waiting, you just like, you are in nature, with the dogs and people are talking and you are like 'Please, just shut up! Just enjoy nature and that's it'." Also, the sounds of cameras and mobile phones caused perplexity, confusion and frustration among the respondents. As one tourist commented, 'You know when you turn your digital camera on, that 'tiding'. Oh, that noise, or when they take a picture with a sign, that 'ctshhh'. Oh, you are like: 'Turn it off!” These reactions are understandable considering our modern busy lives with permanent interruptions - an acoustic environment marked by phone calls and text message notifications, among other modern sounds (see Veijola, 2014). Thus, hearing these signals (of modernity and everyday life) during the husky tours disrupts the authenticity of the nature-based experience.

\section{Designing nature-based tourism soundscapes}

In line with Truax (2012), we can argue that nature-based tourism companies should carefully plan and design the soundscape of their services. This implies awareness of the various sounds that appear in a particular service environment as well as their implications for customer experience. Understanding the way tourists perceive the soundscape of a nature-based tourism service offers an opportunity for providers not only to improve their service quality but also to support the co-creation of memorable experiences. Better soundscapes can be created by just supporting desirable sounds and avoiding unpleasant ones appearing in the service environment. For example, in the case of dog sledding, restricting the use of phones and cameras could help to keep the sounds of modern technologies away from the safari experience. The need for pictures capturing the husky tour could be satisfied by having a safari guide responsible for photographing.

In other cases, improving the service soundscape may even require rethinking the original customer journey and its different service moments. In the dog-sledding case, we could consider whether the safari should start by giving the driving instructions as usually happens or if it should start with an encounter and familiarization with the huskies. Indeed, a better understanding of the sled dogs and their behaviour could contribute to a different tourist experience when, for example, listening to the barking at the beginning of the safari. From this perspective, soundscape design becomes driven by sounds and the acoustic experiences of the user, rather than what is more convenient for the producer. 
Nature-based destination planners and managers should also be aware of the impact of sounds on the service offered by their companies. In particular, they need to be attentive when new infrastructure such as airports, roads, railways and windmills, among others, is planned to be introduced in their destination. Indeed, the sounds caused by this type of infrastructure can have detrimental impacts on a nature-based tourism experience. Moreover, discussions on the soundscape also direct our attention toward the need to approach nature-based tourism experience from a multisensory perspective. After all, the visual sense is only one of the body's senses through which tourists experience nature and the service elements constructed around it. So we need to gain a holistic understanding of the role of all body senses in the co-creation of tourism experience in nature.

\section{References}

Bernat, S. (2014). Soundscapes and tourism: Towards sustainable tourism. Problems of Sustainable Development, 9(1), 107-117.

Fesenko, I. (2019). Sensory dimension of tourist experiencescape: Role of sounds in winter husky dog-sledding experiences in Finnish Lapland. Master's Thesis. Rovaniemi: University of Lapland.

Liu, A., Wang, X. L., Liu, F., Yao, C., \& Deng, Z. (2018). Soundscape and its influence on tourist satisfaction. The Service Industries Journal, 38(3-4), 164-181. https://doi.org/10.1080/02642069.2 017.1382479

Mace, B. L., Corser, G. C., Zitting, L., \& Denison, J. (2013). Effects of overflights on the national park experience. Journal of Environmental Psychology, 35, 30-39. https://doi.org/10.1016/j.jenvp.2013.04.001

Pilcher, E. J., Newman, P., \& Manning, R. E. (2009). Understanding and managing experiential aspects of soundscapes at Muir Woods national monument. Environmental Management, 43, 425-435. https://doi.org/10.1007/s00267-008-9224-1

Quan, S., \& Wang, N. (2004). Towards a structural model of the tourist experience: An illustration from food experiences in tourism. Tourism Management, 25, 297-305. https://doi. org/10.1016/S0261-5177(03)00130-4

Rantala, O., \& Valtonen, A. (2014). A rhythm analysis of touristic sleep in nature. Annals of Tourism Research, 47, 18-30. https://doi.org/10.1016/j.annals.2014.04.001

Schafer, R. M. (1983). The soundscape: Our sonic environment and the tuning of the world. Rochester: Destiny Books.

Truax, B. (1999). Handbook for acoustic ecology. Vancouver: Cambridge Street Publishing.

Truax, B. (2012). Sound, listening and place: The aesthetic dilemma. Organised Sound, 17, 193-201. https://doi.org/10.1017/S1355771811000380

Valtonen, A., \& Veijola, S. (2011). Sleep in tourism. Annals of Tourism Research, 38, 175-192. https://doi.org/10.1016/j.annals.2010.07.016 
Veijola, S. (2014). Towards silent communities. In S. Veijola, J. Germann Molz, O. Pyyhtinen, E. Höckert, \& A. Grit (Eds.), Disruptive tourism and its untidy guests: Alternative ontologies for future hospitalities (pp. 68-95). Palgrave Macmillan.

Waitt, G., \& Duffy, M. (2010). Listening and tourism studies. Annals of Tourism Research, 37, 457-477. https://doi.org/10.1016/j.annals.2009.10.017 